\title{
Conservation and efficient utilization of resources: a major indicator of China's economic transformation
}

\author{
Zhang Zhuoyuan
}

Correspondence:

chengjinzhui@gmail.com

Institute of Economics, CASS, 2

Yuetan Beijiaojie, Beijing 100836, China

\begin{abstract}
After more than 30 years of rapid growth, China's economy is increasingly faced with the bottleneck brought about by resources and environment. To achieve a sustained economic growth, more attention should be paid to the safety of the arable land, fresh water, energy, and other important resources. Great efforts should be made to transform the mode of economic development, adjust the economic structure, deepen reform, and expand opening-up. It is necessary to promote the transformation of the growth means characterized by ineffective utilization of resources and extensive expansion to the one characterized by intensive and efficient utilization of resources as well as quality and efficiency so that the economy and society are really going toward the track of scientific development.
\end{abstract}

Keywords: Resource conservation; Efficient use of resources; Economic restructuring

China's economy has grown rapidly since the beginning of 21st century. However, resource bottlenecks have come to increasingly restrict continued growth. In order for the Chinese economy to continue to grow, the mode of economic development must be transformed from an extensive mode, which results in inefficient resource utilization or even mal-use of resources, to an intensive, quality-oriented mode which is resource-efficient. This is the next crucial step for China's socialist modernization.

\section{Resource bottlenecks restricting China's economic development}

China's economy has grown rapidly since the beginning of Reform and Opening-up at the end of 1978. China has experienced more than 30 straight years of economic growth, with a double-digit average annual economic growth rate $(10 \%)$. This has been dubbed a new miracle in the history of economic development. During this period, three major reforms provided most of the drive and vitality to China's economy. The first was the implementation of the rural household contract responsibility system during the early stages of reform. The second was the establishment of the socialist market economic system in 1992. The third was China's accession to the World Trade Organization at the end of 2001. By 2010, China had become the world's second-largest economy, with a per capita gross domestic product (GDP) in 2011 of over US\$5000, entering China into the ranks of upper- and middle-income countries. Although these economic achievements have attracted the world's attention, the past 
30 years of economic growth were driven mainly by extensive expansion, such that nowadays China's economy is becoming increasingly imbalanced, uncoordinated, and unsustainable. In particular, the balance between economic growth and the carrying capacity of resources and the environment becomes increasingly fragile. Resource bottlenecks have become the most prominent problem facing sustained economic growth. Since the outbreak of the international financial crisis in 2008, it has become urgently important to transform the mode of economic development and to build a resourceefficient, environmentally friendly society. It is now widely agreed upon in China that the pursuit of quantitative, expansive economic growth must be replaced by qualityoriented, resource-efficient economic growth.

It was first proposed in the 1990s that China must transform its mode of economic development. In 1995, the Central Committee of the Communist Party of China (CPC) pointed out in its 9th Five-Year Plan that the most essential thrust of the Plan period was to implement two fundamental shifts. The first was the shift from a traditional planned economy to a socialist market economy, and the second was the shift from an extensive economic growth mode to an intensive mode, in order to promote the sustained, rapid, and healthy development of the national economy and social progress at the same time.

In 2005, the CPC Central Committee re-emphasized in its suggestions to the 11th Five-Year Plan the transformation of the economic growth mode. It advocated building a resource-efficient and environmentally friendly society. In my opinion, not enough progress had been made toward implementing the guidelines first put forward in 1995. On the whole, China's extensive growth pattern, which depends mainly on the consumption of resources, has remained basically unchanged. This has had a negative effect on sustained, rapid economic growth. I participated in the drafting of the 11th Five-Year Plan's proposals. A large number of materials had been assembled by the National Development and Reform Commission of China and other departments before the drafting group began to work. I was deeply impressed by the following details. First, China's ratio of important natural resources per capita is much lower than the global average. For example, arable land per capita in China is just $40 \%$ of the global average. Freshwater per capita is just a quarter of the global average. Petroleum, natural gas, and coal reserves per capita come in at just 11, 4.5, and $79 \%$ of the global average, respectively. Iron, copper, aluminum, and other reserves per capita account for just one-sixth, one-sixth and one-ninth of the global average, respectively. Second, China's dependency upon important mineral resources increased from $5 \%$ in 1990 to more than $50 \%$ in 2004. Third, China's GDP in 2004 accounted for only $4 \%$ of global GDP (based on the RMB exchange rate at the time), but it consumed $8 \%$ of the world's crude oil, $10 \%$ of the world's electricity, $19 \%$ of the world's aluminum, $20 \%$ of the world's copper, and $31 \%$ of the world's coal. Fourth, according to the latest Environmental Sustainability Index released in early 2005 by the World Economic Forum in Davos, China ranked 133rd of 144 countries and regions. Under such dire circumstances, the urgent need to transform China's economic growth mode was again highlighted in the 11th Five-Year Plan. It was proposed that the extensive growth mode of high inputs, high consumption, high emissions, and low efficiency should be transformed to a growth mode of resource-efficiency, low consumption, and low emissions. Particular emphasis was placed on energy conservation and the energy consumption 
per unit of GDP. The Plan set a goal of reducing energy consumption to $20 \%$ lower than the levels during the 10th Five-Year Plan period.

The transformation of the economic development mode was again emphasized in the report of the 17th CPC National Congress in 2007. The congress declared that the following three shifts needed to be realized in order to transform the growth mode: the shift from investment and export driven economic growth toward growth driven by the coordination of consumption, investment, and export; the shift from growth driven mainly by secondary industry to growth driven mainly by the coordination of primary, secondary, and tertiary industries; and the shift from growth that relies heavily on increasing consumption of material resources to growth that relies mainly on scientific and technological progress, improvement in the quality of the workforce, and innovations in management.

At the end of 2009, the Central Economic Work Conference once again stressed the urgency of transforming the mode of economic development. Shortly thereafter in 2010, the Central Committee put forward that the most crucial objective of the 12th Five-Year Plan was to accelerate the transformation of the mode of economic development. The Central Committee also proposed to change the mode of development primarily by strategically altering the economic structure. The Committee also proposed the construction of a resource-efficient and environmentally friendly society as an important means to transformation.

The Central Committee has stressed the importance of transforming the mode of economic growth over and over since 2005, but very little progress has been made as a result of various difficulties and fierce resistance. Local governments in many regions are often willing to pay heavy resource and environmental costs to maintain rapid economic growth and short-term GDP gains. As China is still in the process of industrialization and urbanization, it will be necessary to invest a substantial amount of resources in infrastructure construction. If China is unable to use resources in a better, more intensive manner, the economic prospects for the nation will be bleak. The gargantuan size of China's economy today necessitates a hasty transition. If this issue is not addressed, it will be easy to fall into the "middle-income trap", but difficult to achieve the central government's ambitious modernization objectives.

After more than 30 years of rapid growth, China's economy has come to a new crossroad. Today, we are faced with the task of transforming the mode of our economic development, removing resource and environmental bottlenecks restricting continued growth, and bringing both economic and social development in line with the principles of scientific development.

\section{The security of arable land, fresh water, energy, and other important resources}

To maintain sustained, rapid growth of the Chinese economy, we should pay more attention to the security of such important resources as arable land, fresh water, and energy. China is a large developing nation with a population of over 1.3 billion. Without a stable supply of important material resources, it will be difficult to both maintain economic and social stability and to maintain healthy development of the economy and society. By "security of resources", I mean maintaining both adequate quantity and acceptable quality of resources. For example, ample supply of drinking water is of 
utmost importance to human beings, as is arable land. If arable land is contaminated with heavy metals, the security of edible agricultural products will be threatened. The commercial trade of resources must also be safeguarded. In a market economy, so long as the prices of resources are affordable, investment and transportation channels are unblocked, and competition is relatively fair, it will be possible to purchase foreign resources.

Among all material resources, arable land and fresh water resources are most fundamental to the survival of that country's citizens. Next is energy supply, which guarantees quality of life and economic development, i.e., industrialization, urbanization, and modernization. In the past, more attention was paid to the problem of the energy security, probably because we were more focused on economic growth and wished to bring about industrialization and urbanization as fast as possible. At the same time, I think it is just as important for us to pay attention to the security of arable land and fresh water resources, for food is humanity's most fundamental need. Without ample food and clothes, man cannot advance. Basic principles of economics inform us that agriculture is the foundation of a nation's economy, and the development of agriculture demands sufficient arable land and fresh water. Without adequate agricultural products, no other industries can be developed.

The realities of China's economic growth inform us that the "short board" of China's economy is agriculture. Every severe crisis or serious imbalance to China's economy has been caused by an agricultural crisis or crop failures, and every sharp rise of prices since the founding of the People's Republic of China has been driven by a sharp rise in food prices due to decreased agricultural production. The disaster between the late 1950s and the early 1960s was caused by severely decreased agricultural production, especially grains. Every Chinese person over 60 years old can recall the bitter experience of having not enough to eat at that time. The shortages of food and clothing have been resolved since Reform and Opening, but recently, the country has begun to face the new challenges of economic imbalances and inflation. These are the results of the excess issue of currency, which has resulted in excess liquidity and in the development of agriculture lagging behind the development of other sectors of the economy. Rising food prices often drive up prices in other sectors. In China, it is a mistake to underestimate the importance of agriculture, grain supply, arable land security, and freshwater.

Thus, I think that we must maintain the total amount of arable land in China above 120 million hectares. This is a line we must staunchly defend. We should also recognize that it is unsustainable to push further industrialization and urbanization at the cost of arable land in many regions, especially the central and western regions. China's agricultural security has come under threat due to sharply reduced levels of arable land. As a result, we now import $80 \%$ of edible oils and soybeans in an effort to maintain grain security. Food imports across the board, especially feed grain imports, are on the rise. It is estimated that we would have to restore about 30 million hectares of arable land in order to produce those agricultural products we now import. This is proof that the remaining arable land in China is already insufficient to meet the growing needs of over 1.3 billion inhabitants. If we do not resolutely hold the line at 120 million hectares of arable land, there will be dire consequences if one day we are unable to continue importing food. In order to better hold that line, it will be necessary to ensure that the farmers can profit from growing grain and other agricultural products. However, at 
present, the comparative gains of growing grain and other agricultural products are low. Therefore, it is still necessary to increase national subsidies to "agriculture, farmers, and rural areas". It will also be necessary to maintain policies that benefit agriculture and farmers while also increasing the prices of agricultural products.

\section{Transforming the mode of economic growth, adjusting the structure of economic development, and deepening reforms in order to relieve resource bottlenecks}

First, we must accelerate the transformation of the mode of economic development. Our current extensive resource-consuming mode should be replaced by a resource-efficient, energy-saving mode. Great efforts should be made to increase the efficiency of resource utilization. Transformation will require technological progress, an increased quality of workers, and innovations in management. We must overcome the inertia of our current reliance on increasing inputs of material resources to spur economic growth. Transformation is the linchpin to ensuring continued prosperity, but it is unfortunately much easier said than done. Although transformation of the mode of economic growth was repeatedly stressed in 2011, the elasticity coefficient of energy consumption in that year rebounded to a new high of 0.76, up from 0.58 in 2010, 0.57 in 2009, and 0.41 in 2008. These levels have increased as many local governments have competed to develop high-energyconsuming industries in the pursuit of short-term rapid GDP growth. Over the previous year, 3.48 billion tons of standard coal was burned in China, an increase of $7 \%$ over the previous year. This foiled the plan to reduce national energy consumption per unit of GDP by $3.5 \%$. National energy consumption per unit GDP was reduced by only $2.01 \%$ that year. This goes to show that what we are already doing is not sufficient to promote transformation. To succeed, we will need to take more effective measures.

Second, we should spare no effort to adjust our economic structure. We should set a goal of inhibiting excessive growth of high-energy-consumption, high-emission, and high-pollution industries. We should accelerate the development of low-resourceoccupancy and low-consumption tertiary industry, especially the modern service industry. At present, many industries are operating at overcapacity in China. Some of those are high-energy-consumption industries, such as steel, cement, coal chemical, electrolytic aluminum, shipbuilding, etc. This is the primary reason that it is difficult to alleviate resource bottlenecks in China. Therefore, it will be necessary to inhibit excessive growth of these high-energy-consumption industries once we restructure the economy. At the same time, we should accelerate development of the service industry. More than a decade ago, in 2000, the CPC Central Committee clearly proposed further developing the service industry in the 10th Five-Year Plan. Specifically the Committee proposed to increase the proportion of the service industry within total GDP. However, while GDP tripled from 2000 to 2011, the proportion of the added value of tertiary industries in the GDP increased only $4 \%$. In China, that proportion has hovered around $40 \%$ over recent years, while the current world average is $60 \%$ and that of developed countries is more than $75 \%$. Also, in China, the service industry has been the major absorber of new entries to the labor force and those workers leaving agriculture and manufacturing. From 2005 to 2010, the number of employees in the Chinese service industry grew by 5.79 million on average per year. This fact indicates that it is still necessary to intensify economic restructuring and continue to develop the service industry. 
Third, we should deepen reform and open further to the outside world. How can we better conserve and more efficiently use scarce resources? The experience of many other nations demonstrates that in a market economy, the most effective means to efficient resource utilization is pricing on the free market. A survey by the World Bank indicates that in more than half of the cases documented, price raises were directly responsible for better conservation. The misuse or waste of resources in the past in China was largely due to artificially depressed resource prices. Long-term low prices of land, freshwater, energy, etc. did not accurately reflect the relationship between supply and demand. Today's scarcity of resources and the marred environment are the remnants of that era. China's CPI growth rate was only $1.8 \%$ in 2005 and only $1.5 \%$ in 2006. It was once proposed at the time that China should take advantage of the opportunity to introduce price reforms for scarce resources; however, the proposition was not adopted because the authority was so concerned about how to achieve higher economic growth. Today, we have another low CPI-rate opportunity window which we can use to raise the prices of scarce resource products to a more reasonable level, and promote rational allocation and conservation of resources. As we push reforms, it will be necessary to give compensation to low-income groups so as not to affect their actual income and living standards. At the same time, as the Japanese do, we should make active efforts to develop overseas resources to supplement our domestic short comings. This topic has already been addressed in many other papers and shall not be touched upon here.

Competing interests

The author declares that he has no competing interests.

Authors' information

Zhang Zhuoyuan is an economist and an academician of the Chinese Academy of Social Sciences. His main research interests are political economics, price theory, and market theory.

Received: 1 October 2012 Accepted: 11 October 2012

Published online: 11 December 2015

Submit your manuscript to a SpringerOpen ${ }^{\circ}$ journal and benefit from:

- Convenient online submission

- Rigorous peer review

- Immediate publication on acceptance

- Open access: articles freely available online

- High visibility within the field

- Retaining the copyright to your article

Submit your next manuscript at $>$ springeropen.com 